Buettgen \& Klassen (2020)

\title{
ANSERJ
}

Vol. 11, No. 2

Autumn / Automne 2020

pp. $82-96$

Canadian Journal of Nonprofit and Social Economy Research

Revue canadienne de recherche sur les OBSL et l'économie sociale

\section{The Role of the Nonprofit Sector as a Site for Inclusive Employment}

\author{
Alexis Buettgen \\ McMaster University \\ Thomas R. Klassen \\ York University
}

\begin{abstract}
Employment is a pathway to increased income and empowerment, and improved quality of life and well-being; but for people with disabilities, job opportunities are limited, and employment supports often inadequate. This exploratory study analyzes the role of the nonprofit sector as a site for inclusive employment. Using data gathered from documents and in-depth interviews with nonprofit organizational staff, this study identifies the benefits that can accrue-to individuals, organizations, and communities-when agencies in the nonprofit sector employ persons with disabilities. The presence of employees with disabilities in the workplace increased sensitivity and awareness among all workers, conferred value on disability through an explicit recognition of the particularity of varying lived embodiments, and clarified the notion of dependence.
\end{abstract}

\section{RÉSUMÉ}

Avoir un emploi assure un revenu et une autonomisation accrus ainsi qu'une meilleure qualité de vie et un sentiment de mieux-être. Mais pour les personnes handicapées, les possibilités d'emploi sont limitées et le soutien à l'emploi est souvent inadéquat. Cette étude exploratoire analyse le rôle que joue le secteur à but non lucratif pour assurer un milieu de travail inclusif. Au moyen de données provenant de documents et d'entrevues en profondeur avec le personnel d'organismes à but non lucratif, cette étude identifie les avantages qui se présentent-pour les particuliers, les organisations et les communautés—quand les agences dans le secteur à but non lucratif emploient des personnes ayant des handicaps. À ce titre, la présence dans le milieu de travail d'employés handicapés augmente la conscientisation et la sensibilisation de tous les employés, accorde de la valeur aux handicaps par une reconnaissance explicite de ce que les personnes handicapées peuvent contribuer, et remet en cause la notion de dépendance.

Keywords / Mots clés : Disability; Inclusion; Employment; Nonprofit sector; Misfit / Handicap; Inclusion; Emploi; Secteur à but non lucratif; Inadapté 


\section{Buettgen \& Klassen (2020)}

\section{INTRODUCTION}

People with disabilities in Canada are chronically underemployed and unemployed with fewer economic opportunities, higher rates of poverty, and lower education levels than people without disabilities (Crawford, 2013; Rivera Drew, 2015; Stapleton, 2013; World Health Organization \& World Bank, 2011). In reference to Canada, the United Nations Committee on the Rights of Persons with Disabilities (2017) noted a "persisting gap in the exercise and enjoyment of rights by persons with disabilities" in "work and employment and an adequate standard of living" (p. 13). The poverty of people with disabilities is both a cause and consequence of exclusion from social and economic life (General Assembly Resolution 70/1, 2015; Tardi \& Njelesani, 2015). Employment is a pathway to increased income and empowerment, and improved quality of life and well-being; but for people with disabilities, job opportunities are limited and employment supports often inadequate (Devlin \& Pothier, 2006; ILO, 2015; Oliver, 1990; Thomas, 1999). This article analyzes the role of nonprofit organizations as sites for inclusive employment. Many organizations in the nonprofit sector seek to alleviate poverty and promote community health and well-being, however "little attention is paid to the sector's role as an employer in promoting these same goals" (Van Ymerman \& Lalande, 2015, p. 1).

Few studies have critically investigated the experiences of people with disabilities in the labour market with reference to the form of employment and specific work arrangements (Ellenkamp, Brouwers, Embregts, Joosen, \& Weeghel, 2016; Prince, 2014; Tompa, Scott-Marshall, Dolinschia, Trevithicka, \& Bhattacharyya, 2007). Historically, the literature on disability and employment focused on the need to "cure" or "rehabilitate" individuals with disabilities to fit into the labour market (e.g., Devlin \& Pothier, 2006; Oliver, 1990; Szasz, 1974). This placed responsibility on the individual rather than looking to societal norms and practices that could be modified to better accommodate people with disabilities. Employment in the nonprofit sector has been relatively absent in the small body of literature on disability and employment in Canada, notwithstanding that nonprofit organizations make up a large and diverse sector of the labour market (e.g., Crawford, 2012; Wilton, 2006). The sector includes advocacy and religious organizations; voluntary sports groups; parent and school-based associations; arts and culture organizations; and social, health, and human service provision agencies (Baines, Cunningham, Campey, \& Shields, 2014).

This exploratory article uses data gathered from a broad study that investigated how workplace environments influence the employment experiences of people with disabilities, and the role of the nonprofit sector as a site for inclusive employment. Rosemarie Garland-Thomson's (2011) concept of misfit is utilized to describe how valuing disability in nonprofit service-providing organizations clarifies notions of dependence and emphasizes the particularity of varying lived embodiments. The experiences of individuals working in nonprofit service-providing organizations is studied via in-depth interviews with organizational leaders and employees with disabilities, as well as an analysis of organizational documents.

To set the research context of this analysis, this article begins with a brief review of the literature on disability and employment in Canada in terms of human rights, followed by a description of the nonprofit social-services sector as a potential site for inclusive employment. Next, the conceptual framework and methodology is summarized. The findings are framed in relation to three key aspects of the concept of misfit (Garland-Thomson, 2011) in the context of nonprofit workplaces. The article concludes with reflections on how the experience of misfitting from the standpoint of employees with disabilities in the workplace benefits individuals, organizations, and communities.

\section{THE RESEARCH CONTEXT}

\section{Disability and employment in Canada}

According to Statistics Canada, one in five Canadians (or 6.2 million) aged 15 years and over identify as having a disability (Morris, Fawcett, Brisebois, \& Hughes, 2018). In this article, disability is defined, according to the UN Convention on the 


\section{Buettgen \& Klassen (2020)}

Rights of Persons with Disabilities (2006), as "Persons with disabilities include those who have long-term physical, mental, intellectual or sensory impairments which in interaction with various barriers may hinder their full and effective participation in society on an equal basis with others" (p. 4). This definition is consistent with the human rights model of disability, which moves away from viewing people as problems toward viewing them as holders of rights (Quinn \& Degener, 2002). The human rights model for people with disabilities is inspired by the values of dignity, autonomy, self-determination, equality, and the ethic of solidarity. This model states that "Each individual is deemed to be of inestimable value, and nobody is insignificant. People are to be valued not just because they are economically or otherwise useful but because of their inherent self-worth" (Quinn \& Degener, 2002, p.14). Likewise, Lynne M. Healy (2008) argues that the social work profession expresses human rights principles of respect, dignity, and self-determination. These values are also embedded in legislative codes of rights and codes of ethics for practitioners (Ife, 2008). Human rights are particularly important for social service workers when making decisions that concern the individual needs of service users.

Despite current legislative commitments to human rights, people with disabilities experience significantly lower employment rates than people without disabilities (e.g., Statistics Canada, 1993, 2003, 2008), with some modest improvements in recent years (Crawford, 2016; Ministry of Community and Social Services, 2012; Rioux \& Patton, 2014). Figure 1 reveals a stable employment gap between people with and without disabilities over nearly a decade.

Figure 1: Rates of full-year, full-time employment for people with and without disabilities from 2003-2011, Canada (Crawford, 2016)

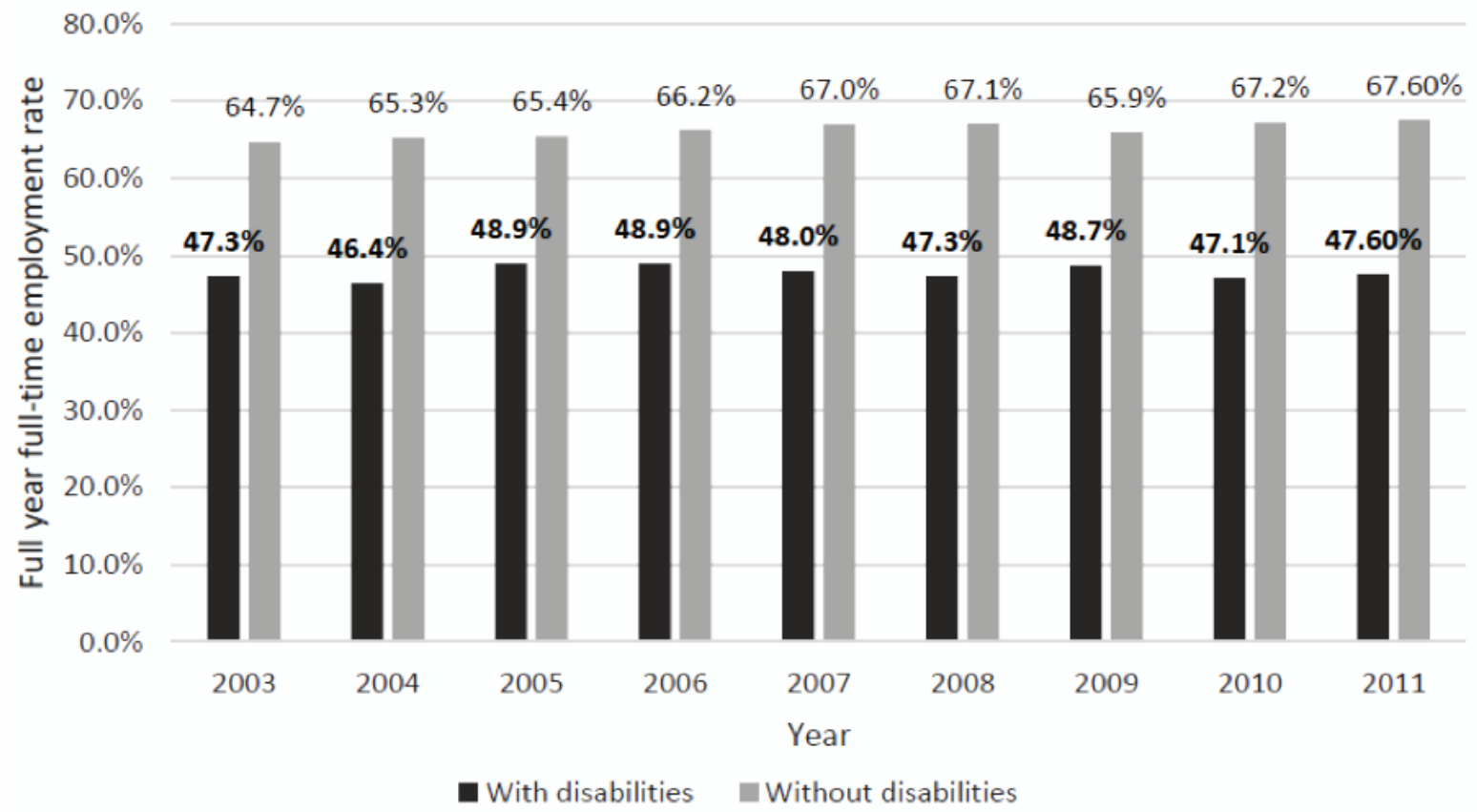

Some critical disability studies scholars argue that this discrepancy is related to apparently progressive social policies that appear to be engaging with disabled people's desires and aspirations for employment, while at the same time purposely "ignoring the complex social aspects of disablement and employment" (Jolly, 2003, p. 519; see also Galer, 2018; Prince, 2004; Wilton, 2006; Wilton \& Schuer, 2006; Withers, 2012). The literature identifies barriers that help explain the underrepresentation of people with disabilities in Canadian workplaces, including employer discrimination and bias (Hernandez, McDonald, Divilbiss, Horin, Velcoff, \& Donoso, 2008; Jakobsen, 2009), concerns by employers about the productivity of workers with disabilities (Houtenville \& Kalargyrou, 2012), poor matches between employee capacity and work requirements (Bonnaccio, Connelly, Gellatly, Jetha, \& Martin Ginis, 2020; Jakobsen, 2009), and employers' worries 


\section{Buettgen \& Klassen (2020)}

about legal liability (Kaye, Jans, \& Jones, 2011). Employers also tend to have limited awareness of workplace accommodations that can be put in place (Kaye et al., 2011; Unger \& Kregel, 2003) or have misconceptions about the costs of accommodations (Houtenville \& Kalargyrou, 2012).

\section{The Ontario nonprofit service-providing sector}

Ontario is the most populous of Canada's 13 sub-national jurisdictions, with a nonprofit service-providing sector (NPSS) composed of organizations defined by their "orientation to serve a public or group good, through private non-profit-making organizational forms" (Baines, Cunningham, Campey, \& Shields, 2014, p. 76). Nonprofit service-providing organizations are typically driven by a mission to serve the disadvantaged. The NPSS constitutes between one quarter to one third of the Ontario nonprofit sector (Baines et al., 2014; Ministry of Citizenship and Immigration Ontario, 2013). The sector consists of approximately 14,000 organizations, 150,000 full-time workers, and 100,000 part-time workers (Statistics Canada, 2009; Van Ymerman \& Lalande, 2015). Most nonprofit organizations are small employers (less than 50 employees), and many have no paid employees at all. Of organizations with at least one paid employee, 58 percent have between one and four employees. Conversely, large employers (over 100 employees) make up only 3.1 percent of organizations in the sector, yet are responsible for 53 percent of the sector's employees (Statistics Canada, 2004).

A feature of the NPSS is the passion that many workers feel toward their organization's mission. Many of those who choose to work in the sector have done so "because of concerns around social justice or making the world a better place" (Van Ymerman \& Lalande, 2015, p. 20). However, several authors have analyzed precarity in the NPSS, characterized by low levels of retirement and benefits coverage, high rates of part-time and contract work, underinvestment in training and development, and struggles in work/life balance for workers (e.g., Baines, 2011; Baines, Cunningham, \& Shields, 2017; Kelly \& Caputo, 2011; Van Ymerman \& Lalande, 2015). Jamie Van Ymerman and Lisa Lalande (2015) suggest that nonprofit organizations can act as "champions of working conditions that ensure dignified and supportive work environments for employees, as well as support the overall health and effectiveness of the [nonprofit] sector" (p. 1). Similarly, Robert Wilton and Stephanie Schuer (2006) suggest there might also be a greater willingness to accommodate employees with disabilities in nonprofit versus for-profit workplaces. Their research found evidence of this among participants in their study of the experiences of workers with disabilities in various industries in Ontario. These authors note that the greater frequency of accommodation in nonprofit workplaces is not surprising, given their organizational logic to serve the less advantaged. While this evidence is encouraging, further research is needed to examine the impact of market discipline on the relatively accommodating climate of nonprofit workplaces (Baines, Cunningham, \& Shields, 2017; Lewchuk, Laflèche, Procyk, Cook, Dyson, Goldring, Lior, Meisner, Shielfs, Tambureno, \& Viducis, 2015; Malenfant, Nichols, \& Schwan, 2019; Wilton \& Schuer, 2006).

\section{Conceptual framework and methodology}

This multisite qualitative study explores the contributions of people with disabilities working in the Ontario NPSS to their organizations. The concept of misfit is utilized to frame the lived identity and experience of disability. The concept of a misfit and the situation of misfitting as articulated by Garland-Thomson (2011) elaborates a materialist feminist understanding of disability by considering how the particularities of embodiment interact with the environment in both its spatial and temporal aspects. Garland-Thomson defines the concept of misfit as:

First, the concept of misfit emphasizes the particularity of varying lived embodiments and avoids a theoretical generic disabled body that can dematerialize if social and architectural barriers no longer disable it. Second, the concept of misfit clarifies the current feminist critical conversation about universal vulnerability and dependence. Third, the concept of misfitting as a shifting spatial and perpetually temporal relationship confers agency and value on disabled subjects at risk of social devaluation by highlighting adaptability, resourcefulness, and subjugated knowledge as potential effects of misfitting. (p. 592, emphasis added) 


\section{Buettgen \& Klassen (2020)}

The utility of this concept is to make diverse identities more visible, and to emphasize context and environment, relation over isolation, and the discrepancies between various bodies and the world. The built and arranged spaces through which individuals navigate their lives (such as workplaces) tend to fit the majority bodies and creates misfits with minority forms of embodiment, such as people with disabilities. This misfitting highlights opportunities for the greater inclusion of diverse bodies and raises awareness of the particular needs of individuals in a community context.

\section{Participants}

For this study, a criterion-based purposive sampling strategy was used to recruit participants from three nonprofit service-providing organizations that had received external recognition for exceptional workplace diversity and inclusiveness programs and/or had a documented history of commitment to inclusion in employment practices. To protect confidentiality and anonymity, the three selected organizations are referred to here as Organization A, Organization B, and Organization $\mathrm{C}$, and pseudonyms are used for individual participants.

Organizations A and B were small (less than 50 staff) consumer-driven disabled peoples' organizations (DPOs) that offered disability services and supports and had a history of employing people with disabilities. As DPOs, both organizations were led by a board of directors whose members included a majority of people who identified with a disability. In each organization, 30 to 40 percent of the staff identified as persons with a disability.

Organization $\mathrm{C}$ served people with and without disabilities, was not a DPO, and had a broader mandate of services and supports for individuals and families. Organization $\mathrm{C}$ had received recognition and awards for diversity and inclusion in the workplace. This large unionized organization had more than 500 staff members, and approximately six percent of all staff identified as persons with a disability. Table 1 summarizes key features of the organizations.

Table 1: Description of participating organizations

\begin{tabular}{|l|c|c|c|}
\hline Organization & A & B & C \\
\hline Total budget & Over $\$ 10,000,000$ & Less than $\$ 1,000,000$ & Over $\$ 10,000,000$ \\
\hline Total number of staff & Less than 50 & Less than 50 & Over 500 \\
\hline$\%$ of total staff who identified as persons with a disability & $30 \%$ & $40 \%$ & $6 \%$ \\
\hline Disabled person's association (DPO) & Yes & Yes & No \\
\hline Unionized & No & No & Yes \\
\hline
\end{tabular}

Participants included six senior leaders (e.g., executive directors, directors, human resources [HR] representatives, and union representatives) and nine front-line employees with disabilities who took part in-depth interviews that were recorded and transcribed verbatim. Two senior leaders were recruited from each organization. Employees with disabilities included three from Organization A, two from Organization B, and four from Organization C. The majority of participants (frontline employees and senior leaders) described themselves as female. Most employees financially supported children or other family members at home, and two described themselves as single parents. Employees with disabilities had various long-term and permanent disabilities, including psycho-social, physical, and visual impairments, and environmental sensitivities. The majority of employees were front-line workers. All employees had a postsecondary education, either a college, bachelor's, or master's degree, in social work and/or the social sciences prior to starting their current job. All participants were employed in full-time positions, most of which were permanent. A few participants were working in temporary contract positions with the potential for extension or permanency. Much personal information about the participants 


\section{Buettgen \& Klassen (2020)}

is suppressed to keep the focus on the institutional processes they describe (DeVault \& McCoy, 2006). Participants are primarily identified by their position in the institutional work process (e.g., employee, executive director, HR representative, or union representative).

Data collection also involved an analysis of organizational documents, including HR policies and procedures, strategic plans, annual reports, accessibility policies, and sample accommodation plans, as well as relevant laws, policies, and legislation informing organizational documents. The Office of Research Ethics at York University reviewed and approved all study procedures.

\section{DATA ANALYSIS}

Data analysis started with verbatim transcripts from interviews with employees with disabilities to discern their subjective experiences in the workplace. Analysis proceeded to investigate how the structure of the workplace in each organization included or excluded employees with disabilities. Perspectives and explanations of events from interviews with senior leaders at each organization have been included. Questions of validity involved referencing back to employees about what they described during interviews. Organizational documents also offered an additional source of data to verify what participants said.

\section{FINDINGS}

The findings are framed in relation to three key aspects of the concept of misfit, namely conferring value on disability, clarifying the notion of dependence, and emphasizing the particularity of varying lived embodiments (Garland-Thomson, 2011). The following three sections illustrate these aspects in relation the experiences of individuals working in the NPSS.

\section{Conferring value on disability}

Garland-Thomson (2011) suggests that the concept of misfitting confers "value on disabled subjects at risk of social devaluation by highlighting adaptability, resourcefulness, and subjugated knowledge as potential effects of misfitting" (p. 592). Employees with disabilities who participated in this study fell into various devalued social categories of disability. These employees described how they drew on their personal experiences of disability-related exclusion, marginalization, discrimination, and abuse to aid others with similar experiences. They described how their experience of disability in society motivated them to work and enhance the efforts of their organizations in the NPSS.

For example, Deidre, an employee at Organization A said, "From a very early age I always had a need or sense or desire to support people [and] see them develop to their potential. ... It sort of became an innate characteristic ... to [want to] be in the so-called helping profession." Similarly, most other employees talked about their organization's philosophy as a driving force for their interest and motivation to do their job. They expressed a match between their values and the values of the organization. When asked what their ideal job would be, most employees said that their current job reflected their ideals. At Organization C, Jane said, "I think what I'm doing now is pretty well my ideal job. It's interesting, it's challenging. ... It's in a team environment with client contact. ... So it feels meaningful, because ... I help people."

Senior leaders said that employing people with disabilities helped their organizations achieve their mission. The employment of people with disabilities helped to align workplace practices with service ideology and reflect the diversity of the communities served. For example, Brett, the executive director at Organization B, said, "[During] hiring, disability is a really important aspect.... We used to have this old rubric where we'd give values, like a point system [during interviews and] ... 10 points [were awarded] if somebody identified as a person with a disability." Given that the organization supported people with disabilities, job candidates with disabilities were rated positively because their lived experiences were 


\section{Buettgen \& Klassen (2020)}

considered a potential contribution to the organization's goals. Thus, disability status served as a basis for evaluation. The organization's values shaped the hiring evaluation process, which determined the salience and potential consequences of candidates' disability status.

Similarly, senior leaders at Organization A placed explicit value on disability status. Senior managers and board members were themselves persons with disabilities, which indicated a perception of disability status associated with leadership and success in the organization. Sarah, the executive director, said that management aimed to foster workplace values that aligned with the organization's service philosophy. She remarked that the organization was guided by a set of principles outlining that, "People with disabilities are the experts on their own needs, so if you believe that for the people you serve, then you believe that for your employees as well." According to several employees at Organization A, its service philosophy permeated into the work environment and was lived through mostly informal, cooperative actions between staff and management.

At Organization C, Jamie, the HR manager, noted, "We generally want our workforce to reflect the people out in the community and we're trying to bring that in line. ... We're trying to look at systemic barriers to employment ... to see how we are addressing those." Interviews with employees and senior leaders, and a review of organizational documents (e.g., collective agreements, the HR manual, the code of ethics, a workforce census, etc.) at Organization $\mathrm{C}$ revealed that senior leaders were seeking to forge what Sandra E. Spataro (2005) describes as a culture of integration. A culture of integration involves highlighting and seeking out the potential benefits of individual differences, including bringing new insights into service development, enhancing group decision quality and creativity, and enriching the set of experiences and perspectives that comprise the work environment. This culture is built on the premise that creativity and decisionmaking processes benefit from differences among co-workers.

\section{Clarifying the notion of dependence}

"Interdependence rather than independence [and] becoming more aware that all people rely on one another for life tasks and survival" (Garland-Thomson, 2011, p. 603) is a feature of many social movements (e.g., Fineman, 2005; Galer, 2018; Prince, 2009; Young, 2005). People with disabilities highlight ways to promote interdependence, participation, and inclusion in public life (Garland-Thomson, 2011). All employees with disabilities who participated in this study said they had received some form of workplace accommodation that enabled a sense of interdependence and mutual support in their jobs.

For example, Katie, an employee at Organization A, compared her job in the NPSS to her previous experiences working in the private sector, saying:

It's way more comfortable here. People are much nicer. It's a lot less cutthroat. Like you don't feel like your competing with other employees for benefits or hours. ... You can collaborate but its not like my co-worker and I are handed a list to see what we can do the fastest.

This excerpt reflects how Katie's experience was hooked into Organization A's relatively non-hierarchical structure and reward system. Senior leaders at Organization A fostered cooperative task interaction between staff in different program areas, which avoided competition and increased collaboration. Sarah, the executive director at Organization A, explained that collaborative work processes were designed to encourage employees from different departments to work together to meet the various needs of employees and service users. Katie also said that since starting work at Organization A, Quinn, one of the directors, would "check in with me about once a week to see how things are going and if l'm happy." These emotionally positive supervisor attitudes toward employees with disabilities were similarly influenced by the organizational structure, which included senior leaders with disabilities, and the level of comfort in being around people with disabilities. As Quinn commented, "I have a disability, as do a good portion of my colleagues, and it's just not that big of a deal." 


\section{Buettgen \& Klassen (2020)}

Other front-line employees at Organization A received accommodations to support their caregiving responsibilities as parents, including single mothers, usually in the form of flexible hours and scheduling to accommodate childcare. In this way, Organization A demonstrated a universal accommodation process that promoted a sense of mutual support and accounted for each individual's unique circumstances and needs. Quinn described the accommodations process as "part of the furniture" of the organization, in the sense of it being an integral part of operations.

The workplace accommodation process for all employees in this study was similar across all three organizations and developed from the standpoint of employees with disabilities. This process involved employees making a request for accommodation or employers identifying a potential need for accommodation. Participants named two factors that influenced the likelihood of employees requesting accommodations: the employee's awareness of the workplace accommodation process and their knowledge of the right to reasonable accommodation in accordance with the law.

Management had a pivotal role in the accommodation process for employees with disabilities. Some senior leaders provided effective accommodation to their employees with disabilities simply by showing a positive attitude and offering empathy and emotional support when needed. Especially successful in this endeavour were leaders who used accommodations to defuse hostile work environments or interpersonal conflicts that could negatively impact employees. For example, Brett described working toward a positive, welcoming, and accommodating team environment at Organization B to support all employees without waiting for accommodation requests. Specifically, he said, "We make sure we fully accommodate without waiting for a request [and] keeping confidentiality [which] I think is a big part of it. Not allowing for those kinds of opportunities to have closed-door gossip sessions [among employees about others' accommodations]." Brett's implementation of workplace accommodations reflects a recognition of the shared need for care from others and embraces the notion of dependence (Garland-Thomson, 2011).

Across all three organizations, some employees described taking up an advocacy role to educate co-workers on biases and stereotypes regarding people with disabilities. For example, Elizabeth, an employee at Organization $\mathrm{C}$, described how she wanted to raise awareness among her co-workers about what it meant to be a person with a psycho-social impairment. Elizabeth expressed concerns about her co-worker's negative stereotypes of service users with psycho-social impairments and said:

They'll say, "Oh I have a client who's bipolar"... so my ears will perk up like what does that mean? Because we don't know what that means. ... And l'll say: "Tell me more. Bipolar can be fun. Bipolar can be fine. Just tell me what you're worried about."

Elizabeth worked to open up a dialogue with her co-workers to present herself as a new image of a person with psychosocial impairments. Elizabeth's efforts reflected the concept of misfitting as a way of putting embodied life at the centre of understanding interpersonal relations, subject formation, and felt and ascribed identities.

\section{Emphasizing the particularity of varying lived embodiments}

Attending to the experience of misfitting from the standpoint of people with disabilities "cultivates the rich particularity that makes up embodied human diversity" (Garland-Thomson, 2011, p. 603; see also Smith, 1997, 2005). According to senior leaders that participated in this study, employing people with disabilities engaged their particular knowledge, experiences, and perspectives in the work of the organization. Workers with disabilities created the opportunity for disability to become an explicit part of the systematic knowledge and techniques of the profession. At Organization B, Brett said:

We promote inclusive community, societies, workspaces, schools, this is what we do day to day. So, we want to make sure we model that as well. ... It's really important for [our organization] to take a leadership role in developing, mentoring, and creating an environment where we have more [staff] that identify with a disability. 


\section{Buettgen \& Klassen (2020)}

As a DPO, Brett viewed Organization B as a vehicle for mutual support and solidarity. Similarly, employees with disabilities who worked at Organizations A and B remarked that working at a DPO gave them a sense of a common purpose: promoting their rights to live and work as dignified and respected citizens. For example, Susan, an employee at Organization $B$, said she felt a mutual acceptance and understanding of the embodied experiences of disability at work. The effort of being disabled (e.g., going to medical/paramedical appointments; taking time off to rest and gain energy for their jobs) was recognized, supported, and incorporated into the structure and functioning of the workplace via the organization's personnel policy. As such, Susan said, "When people take time off [for reasons related to a disability] nobody thinks anything of it. It's just an accepted way of working that isn't questioned by any of my colleagues." Susan said this policy is, in part, "what makes this place work." She suggested that a workplace that demonstrates the inclusion of people with disabilities encourages employees to disclose their disability status and, in turn, opens up the opportunity to discuss accommodations and support for workers to be productive and effective in their jobs. Furthermore, Susan also noted that management fostered a welcoming environment for staff. To accomplish this, the manager of Organization B said that candidates are asked during job interviews if they have any accommodation requests, so that "it already puts it out there that we want to make sure that people know that it's a safe environment to talk about disability and accommodation." This approach is articulated in the organization's anti-ableism policy, which states it is committed to "addressing communications, policies and practices in the workplace and in the delivery of services that are based on differential attitudes toward persons who identify as having disabilities."

Unlike Organizations A and B, Organization $\mathrm{C}$ had a formal workplace diversity strategy. A component of the strategy was a regular workforce census to inform current and future planning for increased diversity in the organization. The HR department collected workforce census data from employees anonymously via survey and examined it across seven key categories: racialization, ethnicity, disability, sexuality (i.e., LGBTQ), age, transgendered status, and gender. The seven categories are not exclusive (e.g., one person could fit all the categories). Lastly, the survey data are combined with existing HR information (e.g., employee length of service, employment status, and employment group) to identify organizational gaps, such as a need for increased representation of people with disabilities in management and senior leadership positions.

Alex, a union representative at Organization C, said that employing people with disabilities at the organization broadened the view of members to see that "other people, ideas, challenges, and obstacles are real." Alex suggested that employing people with disabilities garnered greater attention to diverse perspectives on societal challenges and barriers that service users could also experience. She suggested that employees with disabilities could identify the barriers for service users in that community group. Further, employing staff with disabilities could help service users see themselves reflected in the staffing of the organization. Alex said that employing people with disabilities "challenges our own workforce and people who believe that a social worker looks like this, behaves like this, is abled like this." She said that employing workers with disabilities breaks up the stereotypical image of a social service worker (as White, middle class, female, and non-disabled):

So, when you hear service users say, "You don't look like a social worker" ... it makes us question what a social worker is. We don't see [in our image] a worker who has a visible disability. ... So our workforce grows [by employing people with disabilities] and [becomes more] open.

Similarly, Katie, an employee at Organization A said:

Most of the employees have a disability ... and I think it makes a difference in the way services are delivered and people's perception of disability ... because we don't act like social workers. We don't look at people like they're just a case file, [and] just make a list or plan of action and then check them off the list. We understand a little bit more of the intricacies of negotiating life with a disability. 


\section{Buettgen \& Klassen (2020)}

Katie talked about how employees with disabilities carried their subjectivity through to service users via their personal everyday experiences of "negotiating life with a disability." She suggested that disabled social service workers may act differently than other social workers because of their lived experience of disability and marginalization.

\section{DISCUSSION}

Those interviewed indicated that employing people with disabilities as social service workers disrupted stereotypical images and created a new image of both disability and social worker. Participants in this study stated that organizations with a sizable proportion of staff with disabilities enabled employees with disabilities to have a voice of their own, identify needs, express views on priorities, critically evaluate service provision, and advocate for change. As Alex summarized, "The benefit is what we can learn from people with disabilities [in our agency] to better the service that we provide to everyone in the community."

The experience of misfitting in the larger society benefits some employees with disabilities and the nonprofit service-providing organizations that employ them. In the three organizations analyzed here, this is made possible with the support of senior leaders who purposefully sought to employ staff with disabilities, explicitly promoted workplace diversity and offered flexible workplace accommodations. Within such environments, these findings from this study show that misfits can influence workplace culture and practice by deepening organizational knowledge of the needs and interests of service users. The experience of misfitting in terms of marginality, vulnerability, and dependence is no longer considered negative but denotes value to the organization. The findings also reinforce conclusions of recent case-study research that "the employment of people with disabilities contributes significantly to the corporate culture and success of an organization by diversifying its workforce and increasing employer competence when dealing with clients, customers, and employees of varied backgrounds and experiences" (Samant, Soffer, Hernandez, Adya, Akinpelu, Levy, Repoli, Kramer, \& Blanck, 2009, p. 181).

This small-scale study does not universalize a particular experience, nor is it representative of all nonprofit organizations. Rather it has focused on subjects (person with disabilities) and experiences (employment in the not-for-profit sector) that are often absent from organizational research. Doing so, it "attempts to 'give voice' to a group of employees whose narratives are often absent in dominant quantitative accounts of their workplace experiences" (Foster \& Frosh, 2010, p. 560). Findings from this study reinforce previous findings that organizations that value employees with diverse experiences have the capacity to meet the needs of diverse service users (Lindsay, Cagliostro, Albarico, Mortaji, \& Karon, 2018; Page, 2007).

The three organizations in this study resisted a negative conceptualization of "dependent" as being needy and subject to the authority of others (Young, 1990). They fostered cooperation and collaboration between staff with support from senior management and organizational policies to implement workplace accommodations. These three examples demonstrated how organizations deconstructed the dominant image of the disabled person as someone with limited skills and abilities who is a drag on productivity and society.

Further, the employees of these organizations actively sought a re-conceptualization of what it means to be a person with a disability. For example, Elizabeth at Organization $\mathrm{C}$, who advocated for a re-conceptualization of mental illness, illustrates how all persons are subject to the potential for misfitting depending on environments and the perceptions of others. Although misfitting can lead to segregation, exclusion, and alienation from a majority community, it can also foster intense awareness of social injustice, human rights, and "the formation of a community of misfits that can collaborate to achieve a more liberatory politics and praxis" (Garland-Thomson, 2011, p. 597). This analysis echoes the theoretical work of Karl Marx, Paulo Freire, Frantz Fanon, Noam Chomsky, and Michel Foucault, who saw the revolutionary capacity of those outside the mainstream. Foucault (1980) argues that the resurrection of subjugated knowledge, "such as that of 


\section{Buettgen \& Klassen (2020)}

the psychiatric patient, of the ill person ... the delinquent, etc." (p. 82), fosters critical thinking and brings forth a "historical knowledge of struggles [and] ... the memory of hostile encounters which even up to this day have been confined to the margins" (p. 83). In this way, findings from this study illuminated how the experiences of employees with disabilities can enhance organizational capacity to aid service users.

Previous research on employment in Ontario's nonprofit sector identified a need for further research on the sector's capacity, as an employer, to provide decent work that supports the health and well-being of its employees and the communities it serves (Van Ymerman \& Lalande, 2015). The findings illustrate how it is possible to alter elements of the workplace to better fit the need of employees with disabilities, rather than focusing on how to get employees with disabilities to fit into the workplace environment. This study found evidence that there is opportunity for organizations in the nonprofit sector to champion working conditions and policies that ensure dignified work environments, as well as support the overall effectiveness of the sector.

\section{Further research}

The workers with disabilities who took part in this study all had postsecondary education. This is not, nor was it intended to be, a representative sample of the general population. Future research could adapt the approach used in this study to consider the challenges and opportunities for the employment of diverse people with disabilities in the broader nonprofit sector, as well as in other geographic locations. Moreover, while this study builds on both the human rights model and cultural view of disability through an implied recognition of the intersectionality of disability, future research might narrow the focus to specific groups of people, including people with specific ethno-racial and/or gender identities.

This study did not include people with intellectual impairments or people who were Deaf or hard of hearing. These groups were not purposely excluded from the study, however, as participants self-identified to participate, there was no one in this sample who identified with these disability types. People with intellectual impairments and people who are Deaf or hard of hearing may have different experiences of exclusion or inclusion that present opportunities for further research (e.g., Dr. Adam Lodzinski \& Associates, 2005; Jahoda, Kemp, Riddell, \& Banks, 2008). In addition, "as workforces continue to age, there is a need for more research on treatment issues related to disabilities that arise later in life" (Beatty, Baldridge, Boehm, Kulkarni, \& Colella, 2019, p. 123).

\section{CONCLUSION}

Given their placement between the state and civil society, nonprofit service-providing organizations are critical for service users as they provide vital services, facilitate social connections, and promote a measure of well-being for members of their communities (Akingbola, 2020; Milbourne, 2013). The three organizations studied here are also important places of employment for people with disabilities, who can develop their capacities, build social capital, and contribute to their communities.

The concept of misfit was extended to illustrate its practical application in NPSS workplaces to promote a more inclusive social economy. Specifically, empirical evidence of Garland-Thomson's (2011) concept of misfit is provided within a materialist-feminist understanding of disability. The findings reveal that the inclusion of employees with disabilities in the workplace conferred value on disability through an explicit recognition of the particularity of varying lived embodiments; and the inclusion of people with disabilities in the workplace clarified notions of dependence with appropriate, flexible support and accommodation to highlight the benefits of interdependence and mutual support. The materiality that is at the core of this article is the encounter between employees with disabilities (who primarily identified as female) and the particular structure of the NPSS workplaces. 


\section{Buettgen \& Klassen (2020)}

Findings from this study suggest that the presence of employees with disabilities in the workplaces studied created a high level of sensitivity training and awareness for their peers. It appears that having a sizeable number of employees with disabilities is a factor in how influential persons with disabilities were in the organizations. This was particularly apparent in Organizations A and B, which, as DPOs, are defined by a majority number of board members and senior leaders with disabilities. This suggests that misfits (in this study) must reach a critical number that is at least on par with their representation in the general population and inclusive of senior leadership positions to be influential in an organization. In other words, one misfit will cause change, one organization provides an exemplar; but having more people with disabilities

employed in the nonprofit sector could reduce disability-related employment disparities and become a significant pathway to gainful employment for Canadians with disabilities.

\section{REFERENCES}

Akingbola, K. (2020). COVID-19: The prospects for nonprofit human resource management. Canadian Journal of Nonprofit and Social Economy Research, 11(1), 16-20. doi:10.29173/cjnser.2020v11n1a372

Baines, D. (2011). Restructuring and labour process under marketization: A Canadian perspective. In I. Cunningham \& P. James (Eds.), Voluntary organizations and public service delivery (pp. 168-184). London, UK: Routledge.

Baines, D., Cunningham, I., Campey, J., \& Shields, J. (2014). Not profiting from precarity: The work of nonprofit service delivery and the creation of precariousness. Just Labour, 22 (Autumn 2014), 74-93.

Baines, D., Cunningham, I., \& Shields, J. (2017). Filling the gaps: Unpaid (and precarious) work in the nonprofit social services. Critical Social Policy, 37(4), 625-645.

Beatty, J.E., Baldridge, D.C., Boehm, S.A., Kulkarni, M., \& Colella, A.J. (2019). On the treatment of persons with disabilities in organizations: A review and research agenda. Human Resource Management, 58(2), 119-137.

Bonnaccio, S., Connelly, C.E., Gellatly, I.R., Jetha, A., \& Martin Ginis, K.A. (2020). The participation of people with disabilities in the workplace across the employment cycle: Employer concerns and research evidence. Journal of Business and Psychology, 35(2), 135-158.

Crawford, C. (2012). Patterns in the employment of Canadians with disabilities. Paper presented at the Human Resources and Skills Development Canada, Gatineau, QC.

Crawford, C. (2013). Looking into poverty: Income sources of poor people with disabilities in Canada. Toronto, ON: Institute for Research and Development on Inclusion and Society and Council of Canadians with Disabilities.

Crawford, C. (2016). Untying the knots: Furthering decent new employment after the advent of work-limiting disabilit [Unpublished doctoral dissertation]. York University, Toronto, Ontario.

DeVault, M.L., \& McCoy, L. (2006). Institutional ethnography: Using interviews to investigate ruling relations. In D.E. Smith (Ed.), Institutional ethnography as practice (pp. 15-44). Oxford, UK: Rowman \& Littlefield Publishers, Inc.

Devlin, R., \& Pothier, D. (2006). Introduction: Toward a critical theory of dis-citizenship. In D. Pothier \& R. Devlin (Eds.), Critical disability theory: Essays in philosophy, politics and law (pp. 1-24). Vancouver, BC: UBC Press.

Dr. Adam Lodzinski \& Associates. (2005). Toward an enhanced model of specialized employment services delivered by the Canadian Hearing Society to deaf, deafened and hard of hearing consumers. URL: https://www.chs.ca /position-paper-specialized-services-persons-who-are-deaf-and-hard-hearing [July 7, 2016].

Ellenkamp, J., Brouwers, E., Embregts, P., Joosen, M., \& Weeghel, J. (2016). Work environment-related factors in obtaining and maintaining work in a competitive employment setting for employees with intellectual disabilities: A systematic review. Journal of Occupational Rehabilitation, 26(1), 56-69.

Fineman, M.A. (2005). The autonomy myth: A theory of dependency. New York, NY: The New York Press.

Foster, D., \& Frosh, P. (2010). Negotiating 'difference': Representing disabled employees in the British workplace. British Journal of Industrial Relations, 48(3), 560-582.

Foucault, M. (1980). Power/knowledge: Selected interviews \& other writings by Michel Foucault (C. Gordon, Ed.). New York, NY: Pantheon Books. 


\section{Buettgen \& Klassen (2020)}

Galer, D. (2018). Working towards equity: Disability rights activism and employment in late twentieth-century Canada. Toronto, ON: University of Toronto Press.

Garland-Thomson, R. (2011). Misfits: A feminist materialist disability concept. Hypatia, 26(3), 591-609.

General Assembly Resolution 70/1. (2015). Transforming our world: The 2030 agenda for sustainable development. URL: http://www.un.org/ga/search/view_doc.asp?symbol=A/RES/70/1\&Lang=E [February 15, 2020].

Healy, L. M. (2008). Exploring the history of social work as a human rights profession. International Social Work, 51(6), 735-48.

Hernandez, B., McDonald, K., Divilbiss, M., Horin, E., Velcoff, J., \& Donoso, O. (2008). Reflections from employers on the disabled workforce: Focus groups with healthcare, hospitality and retail administrators. Employee Responsibilities and Rights Journal, 20(3), 157-164.

Houtenville, A., \& Kalargyrou, V. (2012). People with disabilities: Employers' perspectives on recruitment practices, strategies, and challenges in leisure and hospitality. Cornell Hospitality Quarterly, 53(1), 40-52.

Ife, J. (2008). Human rights and social work: Towards rights-based practice. New York, NY: Cambridge University Press. International Labour Office. (2015). Decent work for persons with disabilities: Promoting rights in the global development agenda. Geneva, CH: International Labour Office, Gender, Equality and Diversity Branch, Conditions of Work and Equality Department. URL http://www.ilo.org/wcmsp5/groups/public/—-ed_emp/—-ifp_skills /documents/publication/wcms_430935.pdf [February 1, 2020].

Jahoda, A., Kemp, J., Riddell, S., \& Banks, P. (2008). Feelings about work: A review of the socio-emotional impact of supported employment on people with intellectual disabilities. Journal of Applied Research in Intellectual Disabilities, 21(1), 1-18.

Jakobsen, K. (2009). The right to work: Experiences of employees with rheumatism. Journal of Occupational Science, 16(2), 120-127.

Jolly, D. (2003). The government of disability: Economics and power in welfare and work. Disability \& Society, 18(4), 509-522. doi:10.1080/0968759032000081039

Kaye, H.S., Jans, L.H., \& Jones, E.C. (2011). Why don't employers hire and retain workers with disabilities? Journal of Occupational Rehabilitation, 21(4), 526-536.

Kelly, K., \& Caputo, T. (2011). Community: A contemporary analysis of policies, programs and practices. Toronto, ON: University of Toronto Press.

Lewchuk, W., Laflèche, M., Procyk, S., Cook, C., Dyson, D., Goldring, L., Lior, K., Meisner, A., Shielfs, J., Tambureno, A., \& Viducis, P. (2015). The precarity penalty: The impact of employment precarity on individuals, households and communities - and what to do about it. URL: www.pepso.ca [November 3, 2017].

Lindsay, S., Cagliostro, E., Albarico, M., Mortaji, N., \& Karon, L. (2018). A systematic review of the benefits of hiring people with disabilities. Journal of Occupational Rehabilitation, 28(4), 634-655.

Malenfant, J., Nichols, N., \& Schwan, K. (2019). Chasing funding to "eat our own tail": The invisible emotional work of making social change. Canadian Journal of Nonprofit and Social Economy Research, 10(2), 40-54.

Milbourne, L. (2013). Voluntary sector in transition: Hard times or new opportunities? Bristol, UK: Policy Press.

Ministry of Citizenship and Immigration Ontario. (2013). State of the sector: profile of Ontario not-for-profit and charitable organizations, Volume l: Overall report. Toronto, ON: Government of Ontario. URL: https://www.ontario .ca/page/2013-state-sector-profile-ontarios-not-profits-and-charitable-organizations-volume-1-overall-report [June 11, 2017].

Ministry of Community and Social Services. (2012). Canada-Ontario labour market agreement for persons with disabilities 2011-12 annual report. Toronto, ON: Ministry of Community and Social Services.

Morris, S., Fawcett, G., Brisebois, L., \& Hughes, J. (2018). A demographic, employment and income profile of Canadians with disabilities aged 15 years and over, 2017. URL: https://www150.statcan.gc.ca/n1/en/pub/89-654-x 189-654-x2018002-eng.pdf?st=VxFYMfIT [December 3, 2018]. 


\section{Buettgen \& Klassen (2020)}

Oliver, M. (1990). The politics of disablement. London, UK: MacMillan.

Page, S.E. (2007). The difference: How the power of diversity creates better groups, firms, schools, and societies. Princeton, NJ: Princeton University Press.

Prince, M. (2004). Canadian disability policy: Still a hit-and-miss affair. Canadian Journal of Sociology, 29(1), 59-82. Prince, M. (2009). Absent citizens: Disability politics and policy in Canada. Toronto, ON: University of Toronto Press. Prince, M. (2014). Locating a window of opportunity in the social economy: Canadians with disabilities and labour market challenges. Canadian Journal of Nonprofit and Social Economy Research, 5(1), 6-20.

Quinn, G., \& Degener, T. (2002). Human rights and disability: The current use and future potential of United Nations human rights instruments in the context of disability. United Nations. New York, NY, \& Geneva, CH: http://www.ohchr.org/Documents/Publications/HRDisabilityen.pdf [February 21, 2012].

Rioux, M., \& Patton, L. (2014). Employment equity and disability: Moving forward to achieve employment integration and fulfil promises of inclusion and participation. In C. Agócs (Ed.), Employment equity in Canada: The legacy of the Abella Report (pp. 133-155). Toronto, ON: University of Toronto Press.

Rivera Drew, J.A. (2015). Disability, poverty, and material hardship since the passage of the ADA. Disability Studies Quarterly, 35(3): 4947. URL: http://dsq-sds.org/article/view/4947/4026 [August 7, 2017].

Samant, D., Soffer, M., Hernandez, B., Adya, M., Akinpelu, O., Levy, J.M., Repoli, E., Kramer, M., \& Blanck, P. (2009). Corporate culture and employment of people with disabilities: Role of social workers and service provider organizations. Journal of Social Work in Disability \& Rehabilitation, 8(3-4), 171-188. doi:10.1080/15367100903202706

Smith, D.E. (1997). From the margins: Women's standpoint as a method of inquiry in the social sciences. Gender, Technology and Development, 1(1), 113-135.

Smith, D.E. (2005). Institutional ethnography: A sociology for people. Toronto, ON: Alta-Mira Press.

Spataro, S.E. (2005). Diversity in context: How organizational culture shapes reactions to workers with disabilities and other who are demographically different. Behavioural Sciences and the Law, 23(1), 21-38.

Stapleton, J. (2013). The "welfareization" of disability incomes in Ontario. Toronto, ON: Metcalf Foundation. URL: http://metcalffoundation.com/wp-content/uploads/2013/12/Welfareization-of-Disability-Incomes-in-Ontario.pdf [December 1, 2016].

Statistics Canada. (1993). Adults with disabilities: Their employment and education characteristics - 1991 Health and Activity Limitation Survey. Ottawa, ON: Minister of Industry, Science and Technology.

Statistics Canada. (2003). Education, employment and income of adults with and without disabilities - Tables, 2001 Participation and Activity Limitation Survey. Ottawa, ON: Minister of Industry.

Statistics Canada. (2004). Cornerstones of community: Highlights of the national survey of nonprofit and voluntary organizations 2003 revised. Imagine Canada. URL: http://www.imaginecanada.ca/sites/default/files/www/en /library/nsnvo/nsnvo_report_english.pdf [March 1, 2017].

Statistics Canada. (2008). Participation and activity limitation survey 2006: Labour force experience of people with disabilities in Canada. Ottawa, ON: Minister of Industry.

Statistics Canada. (2009). Satellite account of non-profit institutions and volunteering. Ottawa, ON: Statistics Canada. URL: http://www.statcan.gc.ca/eng/nea/list/npiv [February 14, 2020].

Szasz, T. (1974). The myth of mental illness: Foundations of a theory of personal conduct (Revise ed.). New York, NY: Harper \& Row.

Tardi, R., \& Njelesani, J. (2015). Disability and the post-2015 development agenda. Disability and Rehabilitation, 37(16), 1496-1500.

Thomas, C. (1999). Female forms: Experiencing and understanding disability. Philadelphia, PA: Open University Press.

Tompa, E., Scott-Marshall, H., Dolinschia, R., Trevithicka, S., \& Bhattacharyya, S. (2007). Precarious employment experiences and their health consequences: Towards a theoretical framework. Work, 28(3), 209-224. 


\section{Buettgen \& Klassen (2020)}

Unger, D., \& Kregel, J. (2003). Employers' knowledge and utilization of accommodations. Work, 21(1), 5-15.

United Nations Committee on the Rights of Persons with Disabilities. (2017). Concluding observations on the initial report to Canada. New York, NY: United Nations. URL: https://tbinternet.ohchr.org/_layouts/15/treatybodyexternal /Download.aspx?symbolno=CRPD\%2fC\%2fCAN\%2fCO\%2f1\&Lang=en [January 21, 2020]

Van Ymerman, J., \& Lalande, L. (2015). Change work: Valuing decent work in the not-for-profit sector. URL: http:// theonn.ca/wp-content/uploads/2015/11/Report_Changework_ONN-Mowat-TNC_Atkinson_2015-11-25.pdf [September 15, 2017].

Wilton, R. (2006). Working at the margins: Disabled people and the growth of precarious employment. In D. Pothier \& R. Devlin (Eds.), Critical disability theory: Essays in philosophy, policy, and law (pp. 129-150). Vancouver, BC: UBC Press.

Wilton, R., \& Schuer, S. (2006). Towards socio-spatial inclusion? Disabled people, neoliberalism and the contemporary labour market. Area, 38(2), 186-195.

Withers, A.J. (2012). Disability politics and theory. Halifax, NS: Fernwood Pub.

World Health Organization, \& World Bank. (2011). World report on disability. Geneva, CH: World Health Organization. URL: http://www.who.int/disabilities/world_report/2011/en/ [January 5, 2017].

Young, I. M. (1990). Justice and the politics of difference. Princeton, NJ: Princeton University Press.

Young, M. (2005). Section 7 and the politics of social justice. University of British Columbia Law Review, 38(2), 539-560.

\section{ABOUT THE AUTHORS / LES AUTEURS}

Alexis Buettgen is Assistant Clinical Professor (Adjunct) in the School of Rehabilitation Science at McMaster University, Hamilton Ontario, Canada. Email: a.buettgen@gmail.com.

Thomas R. Klassen is a professor in the School of Public Policy and Administration at York University, Toronto, Ontario, Canada. Email: tklassen@yorku.ca. 